Article

\title{
Can Active Aerobic Exercise Reduce the Risk of Cardiovascular Disease in Prehypertensive Elderly Women by Improving HDL Cholesterol and Inflammatory Markers?
}

\author{
Nayoung Ahn and Kijin Kim *D \\ Department of Physical Education, Keimyung University, Daegu 42601, Korea; nyahn13@kmu.ac.kr \\ * Correspondence: kjk744@kmu.ac.kr
}

Received: 12 June 2020; Accepted: 12 August 2020; Published: 14 August 2020

\begin{abstract}
This study aims to verify the efficacy of exercise programs designed to prevent and treat hypertension-induced cardiovascular disease (CVD) by analyzing the effects of a 6-month active aerobic exercise program, administered to prehypertensive elderly women, on reducing the risk of developing CVD by enhancing their physical fitness level and improving the detailed markers of high-density lipoprotein cholesterol (HDL-C) and inflammatory markers. We assigned the elderly women ( $\geq 65$ years) recruited into normal blood pressure (120-129/80-84; NBP, $n=18$ ) and high-normal blood pressure (130-139/85-89; HNBP, $n=12$ ) groups according to the European guidelines for the management of arterial hypertension. The exercise program was made up of combined workouts of elastic band resistance exercise and aerobics with dance music. The program took place three times a week for six months, with each session lasting $60 \mathrm{~min}$. We measured pre- and post-intervention body composition, blood pressure, physical fitness level, blood lipids profile, HDL-C, SAA, TNF- $\alpha$, IL-6, IL-4, IL-15, CRP, and HSP70 and calculated the Framingham risk scores for comparison. A significant post-intervention reduction in the mean systolic blood pressure (SBP) was observed in the HNBP group $(p<0.001)$, with significant increase in HDL-C $(p<0.01)$ and significant decrease in serum amyloid A (SAA) concentration $(p<0.01)$. A significant improvement in physical fitness factors such as physical efficiency index (PEI) was also observed in the HNBP group $(p<0.05)$. The post-intervention TNF- $\alpha$, IL-6, and SAA concentrations were more significantly lower in the HNBP than in the NBP group $(p<0.05)$. Compared to the baseline values, a significant decrease in SAA concentration $(p<0.01)$ and significant increase in HSP70 concentration $(p<0.001)$ were observed in the HNBP group. The HNBP group's 10-year CVD risk was also significantly reduced $(p<0.05)$. The pre-post differences in SBP and DBP were significantly correlated with those in the anti-inflammatory markers IL-4 and IL-15 $(p<0.01)$. In conclusion, the 6-month active aerobic exercise program of moderate intensity administered to prehypertensive elderly women ( $\geq 65$ years) had the effect of reducing the 10-year CVD risk through a substantial reduction in SBP, overall physical fitness improvement, increase in HDL-C, decrease in SAA concentration, and substantial decrease in inflammatory biomarkers. It was also confirmed that an increase in anti-inflammatory markers, which showed a small range of increase with respect to the decrease in blood pressure, may have a major effect.
\end{abstract}

Keywords: hypertension; exercise; inflammation; cardiovascular disease; physical fitness

\section{Introduction}

Responsible for over $50 \%$ of all deaths caused by cardiovascular disease (CVD), hypertension is a major global public health risk factor [1]. The Seventh Report of the Joint National Committee 
on Prevention, Detection, and Treatment of High Blood Pressure (JNC7) defines prehypertension as systolic blood pressure (SBP) readings of $120-139 \mathrm{mmHg}$ or diastolic blood pressure (DBP) of 80-89 $\mathrm{mmHg}$ [2]. Prevalence of prehypertension is high among adults, with the risk of going on to develop chronic hypertension increasing with age [3,4]. In particular, hypertensive CVD causes atherosclerotic vascular lesions and is a leading cause of death worldwide [5,6]. The European guidelines for the management of arterial hypertension [7] subdivided the range of prehypertension into normal blood pressure (120-129/80-84; NBP) and high-normal blood pressure (130-139/85-89; HNBP). HNBP carries CVD risk factors and is associated with a very high prevalence of CVD and coronary artery disease (CAD) [8].

In the prehypertensive stage, pathological conditions including CVD cause high-density lipoprotein cholesterol (HDL-C) to undergo structural changes, thereby impairing its atheroprotective and anti-inflammatory functions, which in turn can impair its protective function by increasing the level of dysfunctional HDL-C [9]. Increased serum amyloid A (SAA), a major acute-phase protein acting as a biomarker of dysfunctional HDL-C, makes HDL-C particles dysfunctional by binding and circulating with them, impairing HDL's antioxidant activity [10]. SAA enrichment in HDL-C molecules acts as a systemic inflammatory marker indicative of an ongoing inflammatory process, during which SAA increases rapidly. High levels of SAA are shown in the CVD high risk group [9], and high enrichment of HDL-C with SAA is closely associated with CVD prevalence and mortality [11]. Furthermore, CVD risk in hypertension patients is more closely associated with the levels of apolipoprotein, which plays a crucial role in the protective functions of HDL, than with the quantitative levels of HDL-C [12], whereby CVD patients have low concentrations of serum apolipoprotein A1 (ApoA1) [13]. Hypertensive CVD patients also show elevated plasma concentrations of tumor necrosis factor- $\alpha$ (TNF- $\alpha$ ), one of the typical inflammatory mediators, and elevated levels of C-reactive protein (CRP) with monocyte and macrophage infiltration and accumulation in artery walls [14]. As examined above, progression from prehypertension to hypertension increases not only biomarkers of metabolic disorders, but also cellular inflammatory markers [15-17]. Moreover, progression to chronic inflammation and CVD, including atherosclerosis, triggered by endothelial cell activation [18], is characterized by accompanying complications $[19,20]$.

The most effective intervention for prevention of hypertension in the prehypertension, in particular HNBP stage is administering an intensive lifestyle change program based on a low-salt diet and regular exercise aimed at achieving and maintaining blood pressure within an optimal range [1]. Studies on the prevention of hypertension and related complications [21-26] attach great importance to exercise programs. It has been reported that the level of fitness enhanced through exercise program has an important effect on blood pressure control [21,27] and greatly contributes to reducing CVD mortality [22,23]. Epidemiological investigation verified the effects of regular aerobic exercise in preventing and treating hypertension and reducing CV risk and mortality. A meta-analysis of randomized controlled trials (RCTs) confirmed that aerobic endurance training, dynamic resistance training, and isometric training had the effects of reducing resting SBP and DBP by 3.5/2.5, 1.8/3.2, and 10.9/6.2 mmHg, respectively [28]. However, these findings are not consistent with the findings of other studies that suggest exercise capacity is not related to blood pressure [29] and that physical fitness level is associated with obesity, but not with blood pressure [30].

Studies investigating the association between exercise and CVD risk factors reported that exercise training has a direct effect on vascular function and structure [30], but changes in traditional cardiovascular risk factors are not correlated with exercise in terms of arterial function and health [31]. However, in a study in which patients with chronic obstructive pulmonary disease (COPD) were treated with aerobic exercise, increase in ApoA1 concentration was observed [13]. In a study analyzing the effects of long-term physical activity, HDL-C and ApoA1 levels were increased by 10 and 11\%, respectively, but no change was observed in the level of SAA component of HDL-C [32]. Regular exercise enhances cell recovery and antioxidant effects. In particular, exercise-induced overexpression of heat shock protein 70 (HSP70) inhibits tissue damage by inhibiting mitochondrial damage [33-35], 
and also inhibits apoptosis of cardiac muscle cells and protects cells [36]. Furthermore, the expression level of superoxide dismutase (SOD), which acts as regulator of oxidative stress suppression in the cardiovascular system, is increased through regular aerobic exercise [37]. A study on exercise treatment of aging rats found that exercise treatment significantly increased the activities of total SOD, mitochondrial SOD, cytoplasmic SOD, and extracellular SOD [38].

However, in the process of analyzing the exercise training effects on free radicals and inflammatory markers in the prehypertension stage, detailed mechanisms related to the effects of treating CVD-related risk factors including functional markers of HDL-C and inflammatory biomarkers are still unclear. Therefore, it is necessary to analyze exercise programs with regard to the symptoms of prehypertension, physical fitness level, inflammatory markers, and heart disease predictors.

Considering the foregoing, this study aims to verify the efficacy of exercise programs designed to prevent and treat hypertension-induced CVD by analyzing the effects of a 6-month active aerobic exercise program, administered to prehypertensive elderly women, on reducing the CVD risk by enhancing their fitness level and improving the detailed markers of HDL-C and inflammatory markers.

\section{Methods}

\subsection{Subjects}

Elderly women ( $\geq 65$ years) were randomly selected for blood pressure (BP) measurement and were assigned to either the normal blood pressure group (120-129/80-84; NBP, $n=18$ ) or the high-normal blood pressure group (130-139/85-89; HNBP, $n=12$ ) according to the European guidelines for the management of arterial hypertension [7] in Table 1. The study subjects were selected from among the members of the Elderly Health Promotion Center (out of 1000 members) in Daegu, South Korea, who viewed the notice and voluntarily agreed to participate. However, it was composed of subjects confirmed by the doctor's diagnosis as having no special diseases except blood pressure. Therefore, the limitation of this study is that the random selection method cannot be considered to be applied in the process of selecting a perfect subject. A total of 40 participants were enrolled (20 in each group), but 30 participants completed the program, with 10 dropouts during the 6-month experimental period (NBP group: $n=2$, HNBP group: $n=8$ ). In the process of selecting candidates among subjects who were allowed to participate through the doctor's diagnosis and randomly classifying them into two groups, the limitation of the sample size was considered as the limitation of this study. We obtained approval for the recruitment and exercise treatment experiment from the Institutional Review Board (IRB) of Keimyung University (40525-201706-BR-27-02).

Table 1. Characteristic of subjects.

\begin{tabular}{ccc}
\hline Variable & NBP $(\boldsymbol{n}=\mathbf{1 8})$ & HNBP $(\boldsymbol{n}=\mathbf{1 2})$ \\
\hline \multirow{2}{*}{ Age $(\mathrm{yr})$} & 69.22 & 72.00 \\
& 4.14 & 3.81 \\
\hline \multirow{2}{*}{ Height $(\mathrm{cm})$} & 154.11 & 152.17 \\
& 4.35 & 5.31 \\
\hline \multirow{2}{*}{ Body weight $(\mathrm{kg})$} & 61.20 & 58.43 \\
& 9.36 & 7.30 \\
\hline \multirow{2}{*}{ BMI $\left(\mathrm{kg} / \mathrm{m}^{2}\right)$} & 25.23 & 25.27 \\
& 3.87 & 2.53 \\
\hline \multirow{2}{*}{$\%$ fat } & 34.06 & 37.08 \\
& 6.03 & 4.09 \\
\hline \multirow{2}{*}{ WHR } & 0.90 & 0.90 \\
& 0.07 & 0.09
\end{tabular}

Values are mean and standard deviation; NBP: normal blood pressure; HNBP: high-normal blood pressure; BMI: body mass index; WHR: waist hip ratio. 


\subsection{Active Aerobic Exercise Program}

The exercise program was made up of combined workouts of elastic band resistance exercise and aerobic dance with music. The program took place three times a week for six months, with each session lasting $60 \mathrm{~min}$. Exercise intensity was set in compliance with the recommendations for seniors on the Borg's rating of perceived exertion (RPE) scale proposed by the American College of Sports Medicine (ACSM) [39]. Prior to beginning the exercise program, the participants were given a detailed explanation of RPE, and the exercise intensity was monitored during the session through continuous communication. The intensity of effort was set at 11-13 (light to somewhat hard) from week 1 to week 12, and 13-15 (somewhat hard to hard) from week 13 to week 24 . The elastic band color was changed every week to build resistance in tune with individual exercise capacity and exercise intensity was progressed by increasing the number of repetitions. The yellow resistance band initially used was replaced by the red band after four weeks, subject to individual exercise capacity. Resistance band exercise for the upper and lower extremities consisted of 10 repetitions of three sets of seven movements (seated rows, elbow flexion, archery pull for posterior shoulder, hip flexion, hip extension, long-sitting ankle plantar flexion), which last $20 \mathrm{~min}$ in total with 1-min break between sets.

An aerobic dance workout to music was sustained for $20 \mathrm{~min}$, with care taken to keep the heart rate (HR) within the range of individual target $\mathrm{HR} \pm 5 \%$ by setting the target $\mathrm{HR}$ at $65-75 \% \mathrm{HRmax}$ (moderate intensity) using the Karvonen formula [(HR max-HR rest) $\times$ exercise intensity $(65-75 \%)+$ HR rest]. The post-exercise heart rate was monitored by measuring the heart rate of the radial and carotid arteries $(\mathrm{HR} / \mathrm{min}=\mathrm{HR} / 15 \mathrm{~s} \times 4)$. The 10-min warm-up and cool-down exercises consisted mainly of stretching. Adjustment of exercise intensity was applied in the range of $65-75 \%$ HRmax as a whole, and was maintained in the range of $65-70 \%$ HRmax in the first half and $70-75 \%$ HRmax in the second half. Control of this intensity was monitored using heart rate and RPE as described above.

\subsection{Body Composition and Function Measurements}

Body height $(\mathrm{H})$ and weight $(\mathrm{W})$ were measured using a stadiometer and InBody 3.0 (Biospace, Korea), respectively. The body mass index (BMI) was calculated using the standard formula: $\mathrm{BMI}=$ $\mathrm{W} / \mathrm{H}^{2}\left(\mathrm{~kg} / \mathrm{m}^{2}\right)$. The senior fitness test of Rikli and Jones was used to measure the physical function and life fitness of the elderly [40]. The Rikli and Jones Senior Fitness Test (SFT) was administered to assess the participants' physical and functional fitness [40]. The SFT assessment items were 30-s chair stand (number of sit-to-stand during $30 \mathrm{~s}$ ), 30-s arm curl (number of arm curl repetitions performed with a 2-kg dumbbell during $30 \mathrm{~s}$ ), chair sit and reach (distance between the fingertips and the toes while reaching forward towards toes without bending the knees, and back scratch (distance between the middle fingers of both hands with the arms placed around the back). In addition, the 10-feet $(\sim 3 \mathrm{~m})$ walk test used in Gill's study was administered to measure the fast walking speed, with the participant rising from a chair, walking $3 \mathrm{~m}$, and returning to the chair. Physical efficiency index (PEI) was calculated using the formula [PEI $=(100 \times$ test duration in seconds $) /(2 \times$ HR Sum in the recovery periods)]. As body composition variables, body fat percentage and waist-to-hip ratio (WHR) were analyzed as well.

\subsection{Blood Collection and Biochemical Analysis}

A fasting $(12 \mathrm{~h})$ blood sample $(10 \mathrm{~mL})$ was collected from each participant through the brachial vein. The collected blood was heparin-treated and centrifuged at $3000 \mathrm{rpm}$ for $10 \mathrm{~min}$, and TC, TG, and LDL-C were analyzed with an enzymatic method using an automatic analyzer (Auto-analyzer Hitachi 7150, Hitachi Ltd., Tokyo, Japan). HDL-C was measured by an enzymatic method using the supernatant after precipitation HDL-C particles using a precipitating agent. Blood glucose was measured using an automatic blood glucose analyzer (YSI 2300, Marshall Scientific, Hampton, NH, USA), and insulin was measured using an insulin ELISA kit (Mercodia, Uppsala, Sweden). Homeostatic model assessment for 
insulin resistance (HOMA IR), an index of insulin resistance, was calculated with the formula described by Matthews et al. [41]: fasting serum insulin $(\mu \mathrm{L} / \mathrm{mL}) \times$ fasting plasma glucose $(\mathrm{mmol} / \mathrm{L}) / 22.5$.

\subsection{Analysis of Pro-Inflammatory and Anti-Inflammatory Markers}

Tumor necrosis factor- $\alpha$ (TNF- $\alpha$ ) and IL-6 were analyzed using Luminex technology (PPX-056_MXCE4A4, 191482000). Enzyme-linked immunosorbent assay (ELISA) was used to analyze CRP (R\&D DCRP00, P183393 kit), SAA (Elabscience ab100635, KA0528 kit), ApoA-1(Abcam ab108804, GR3188830-3 kit), SOD2(Abnova KA0528 kit), and HSP70 (Enzo ADI-EKS-715, 02201818A kit).

\subsection{Calculation of the 10-Year Risk of Heart Disease}

Using the measured values of the corresponding test variables such as gender, age, TC, HDL-C, LDL-Cl, SBP, DBP, diabetes, and smoking status, we calculated a 10-year risk of heart disease with the Framingham risk score [42]. First, after dividing the age of women into nine groups and LDL-C, TC, HDL-C, SBP, and DBP into five groups each, we assigned a risk score to each group. Diabetes, hypertension, and smoking status were treated as binary (yes/no) variables and scores were given accordingly. The scores assigned to the test variables were taken into account in six stages: age in stage 1, either LDL-C or TC in stage 2, HDL-C in stage 3, SBP and DBP in stage 4, diabetics in stage 5, and smoking status in stage 6 . Different scores reflecting LDL-C or TC were assigned across the stages in all variables. The 10-year risk of heart disease was calculated based on the sums of the scores reflecting LDL-C or TC.

\subsection{Statistical Analysis}

Statistical analysis was performed using SPSS version 24.0 (IBM SPSS Statistics, Chicago, IL, USA). The independent $t$-test was used to evaluate intergroup differences in general physical characteristics. Two-way repeated ANOVA was performed to evaluate the significant differences between the groups and the periods, followed by a post-hoc test; when significant differences were found: Mann-Whitney $\mathrm{U}$ test between groups by period and the Wilcoxon test between periods by group. Pearson's correlation was performed to analyze the correlations between the changed post-intervention values of metabolic syndrome predictors and major items. All data were described as mean \pm standard deviation, and the statistical significance level was set at $p<0.05$.

\section{Results}

\subsection{Body Composition}

No significant intergroup and intragroup (pre-post) differences were observed in body weight in Table 2. The mean BMI fell under the obesity class by Korean criteria, with the post-intervention value of body fat percentage (\%fat) significantly higher $(p<0.05)$ in the HNBP group than in the NBP group as well as pre-intervention value of $\%$ fat within the HNBP group. 
Table 2. Change of body composition and cardiovascular disease risk factors after exercise.

\begin{tabular}{|c|c|c|c|c|c|c|c|}
\hline \multirow{2}{*}{ Variable } & \multicolumn{2}{|c|}{$\operatorname{NBP}(n=18)$} & \multicolumn{2}{|c|}{ HNBP $(n=12)$} & \multirow{2}{*}{ Source } & \multirow{2}{*}{ F-Value } & \multirow{2}{*}{$p$-Value } \\
\hline & Pre & Post & Pre & Post & & & \\
\hline \multicolumn{8}{|c|}{ Body composition } \\
\hline \multirow{3}{*}{ Body weight (kg) } & 61.20 & 61.37 & 58.43 & 58.82 & Time & 0.015 & 0.902 \\
\hline & 9.36 & 9.36 & 7.30 & 6.49 & Groups & 1.391 & 0.001 \\
\hline & & & & & $\mathrm{T} \times \mathrm{G}$ & 0.002 & 0.961 \\
\hline \multirow{3}{*}{$\mathrm{BMI}\left(\mathrm{kg} / \mathrm{m}^{2}\right)$} & 25.23 & 25.27 & 25.27 & 25.37 & Time & 0.005 & 0.946 \\
\hline & 3.87 & 3.81 & 2.53 & 2.16 & Groups & 0.007 & 0.932 \\
\hline & & & & & $\mathrm{T} \times \mathrm{G}$ & 0.001 & 0.973 \\
\hline \multirow{3}{*}{$\%$ fat } & 34.06 & 33.56 & 37.08 & $38.97 *$,\# & Time & 0.272 & 0.606 \\
\hline & 6.03 & 6.06 & 4.09 & 3.83 & Groups & 8.160 & 0.008 \\
\hline & & & & & $\mathrm{T} \times \mathrm{G}$ & 0.807 & 0.377 \\
\hline \multirow{3}{*}{ WHR } & 0.90 & $0.87^{\#}$ & 0.90 & $0.87^{\#}$ & Time & 13.440 & 0.001 \\
\hline & 0.07 & 0.05 & 0.09 & 0.05 & Groups & 0.001 & 1.000 \\
\hline & & & & & $\mathrm{T} \times \mathrm{G}$ & 0.001 & 1.000 \\
\hline \multicolumn{8}{|c|}{ Cardiovascular disease risk factors } \\
\hline \multirow{3}{*}{$\mathrm{SBP}(\mathrm{mmHg})$} & 118.44 & 118.89 & $135.67^{* * *}$ & 133.50 ***,\#\#\# & Time & 2.033 & 0.165 \\
\hline & 10.65 & 7.19 & 3.94 & 4.66 & Groups & 33.285 & 0.001 \\
\hline & & & & & $\mathrm{T} \times \mathrm{G}$ & 4.673 & 0.039 \\
\hline \multirow{3}{*}{ DBP (mmHg) } & 77.44 & $78.89^{\#}$ & 83.00 * & 83.33 & Time & 2.621 & 0.117 \\
\hline & 7.97 & 7.19 & 4.22 & 3.89 & Groups & 4.583 & 0.041 \\
\hline & & & & & $\mathrm{T} \times \mathrm{G}$ & 1.024 & 0.320 \\
\hline \multirow{3}{*}{$\mathrm{TC}(\mathrm{mg} / \mathrm{dL})$} & 178.56 & 193.11 & 182.00 & 189.33 & Time & 2.052 & 0.163 \\
\hline & 48.80 & 40.36 & 47.17 & 48.69 & Groups & 0.001 & 0.991 \\
\hline & & & & & $\mathrm{T} \times \mathrm{G}$ & 0.223 & 0.640 \\
\hline \multirow{3}{*}{ HDL-C (mg/dL) } & 54.67 & 55.44 & 51.17 & $57.67^{\# \#}$ & Time & 7.681 & 0.010 \\
\hline & 6.77 & 9.14 & 7.32 & 7.25 & Groups & 0.062 & 0.806 \\
\hline & & & & & $\mathrm{T} \times \mathrm{G}$ & 4.749 & 0.038 \\
\hline \multirow{3}{*}{ LDL-C (mg/dL) } & 111.44 & 126.11 & 105.00 & 116.83 & Time & 4.880 & 0.036 \\
\hline & 41.40 & 36.49 & 34.60 & 41.47 & Groups & 0.359 & 0.554 \\
\hline & & & & & $\mathrm{T} \times \mathrm{G}$ & 0.056 & 0.815 \\
\hline \multirow{3}{*}{$\mathrm{TG}(\mathrm{mg} / \mathrm{dL})$} & 97.67 & 104.78 & $157.33 * * *$ & 124.67 \#\# & Time & 2.224 & 0.147 \\
\hline & 37.59 & 43.48 & 39.04 & 37.04 & Groups & 10.922 & 0.003 \\
\hline & & & & & $\mathrm{T} \times \mathrm{G}$ & 5.389 & 0.028 \\
\hline \multirow{3}{*}{ Insulin } & 7.56 & 8.14 & 6.30 & $9.00 \#$ & Time & 5.692 & 0.024 \\
\hline & 3.79 & 3.21 & 2.45 & 2.29 & Groups & 0.046 & 0.832 \\
\hline & & & & & $\mathrm{T} \times \mathrm{G}$ & 2.345 & 0.137 \\
\hline \multirow{3}{*}{ Glucose } & 91.78 & 95.89 & $110.00 * *$ & $123.67 * *$ \#\# & Time & 25.080 & 0.001 \\
\hline & 10.97 & 18.45 & 23.53 & 31.83 & Groups & 8.963 & 0.006 \\
\hline & & & & & $\mathrm{T} \times \mathrm{G}$ & 7.246 & 0.012 \\
\hline \multirow{3}{*}{ HOMA IR } & 1.68 & 1.95 & 1.64 & 2.77 * & Time & 9.791 & 0.004 \\
\hline & 0.79 & 0.91 & 0.54 & 1.26 & Groups & 2.403 & 0.132 \\
\hline & & & & & $\mathrm{T} \times \mathrm{G}$ & 3.714 & 0.064 \\
\hline
\end{tabular}

Values are mean and standard deviation; NBP: normal blood pressure; HNBP: high-normal blood pressure; BMI: body mass index; WHR: waist hip ratio; SBP: systolic blood pressure; DBP: diastolic blood pressure; TC: total cholesterol; HDL-C: high density lipoprotein cholesterol; LDL-C: low density lipoprotein cholesterol; TG: triglyceride; HOMA IR: homeostatic model assessment insulin resistance; T: time; G: groups; ${ }^{*} p<0.05,{ }^{* *} p<0.01,{ }^{* * *} p<0.001$, vs. NBP group: Mann-Whitney test between groups; $\# p<0.05$, \#\# $p<0.01$, \#\#\# $p<0.001$ vs. pre: Wilcoxon test between time. 


\subsection{CVD Risk Factors}

SBP decreased significantly $(p<0.001)$ by $2.1 \mathrm{mmHg}$ in the HNBP group after the exercise program, but DBP remained unchanged. HDL-C increased significantly $(p<0.01)$ and TG concentration decreased significantly $(p<0.01)$ in the HNBP group after the exercise program in Table 2. In particular, the pre-intervention values were significantly higher $(p<0.001)$ in the HNBP group compared with the NBP group. Significantly higher post-intervention values were observed in the levels of blood insulin $(p<0.05)$ and glucose $(p<0.01)$ in the HNBP group, but not in HOMA IR. Compared with the NBP group, however, the HNBP group showed significantly higher post-intervention levels of glucose $(p<0.01)$ and HOMA IR $(p<0.05)$.

\subsection{Physical Fitness}

No intergroup differences were observed in physical fitness factors except for arm curl. In the intragroup pre-post comparison, the HNBP group showed significant improvements in the chair sit and reach $(p<0.05), 30$-s chair stand $(p<0.001)$, arm curl $(p<0.01)$, and PEI $(p<0.05)$, as did the NBP group in back scratch $(p<0.01), 30$-s chair stand $(p<0.001)$, and arm curl $(p<0.01)$ in Table 3.

Table 3. Change of physical fitness after exercise.

\begin{tabular}{|c|c|c|c|c|c|c|c|}
\hline \multirow{2}{*}{ Variable } & \multicolumn{2}{|c|}{$\operatorname{NBP}(n=18)$} & \multicolumn{2}{|c|}{ HNBP $(n=12)$} & \multirow{2}{*}{ Source } & \multirow{2}{*}{$F$-Value } & \multirow{2}{*}{$p$-Value } \\
\hline & Pre & Post & Pre & Post & & & \\
\hline \multirow{3}{*}{$\begin{array}{l}\text { Chair sit and } \\
\text { reach }(\mathrm{cm})\end{array}$} & 21.88 & 21.26 & 17.45 & $22.50^{\#}$ & Time & 5.531 & 0.027 \\
\hline & 3.11 & 6.80 & 3.76 & 6.59 & Groups & 1.603 & 0.217 \\
\hline & & & & & $\mathrm{T} \times \mathrm{G}$ & 4.190 & 0.051 \\
\hline \multirow{3}{*}{$\begin{array}{l}\text { Back scratch } \\
\text { (Right, cm) }\end{array}$} & -7.02 & $-4.00^{\# \#}$ & -9.88 & -7.25 & Time & 2.548 & 0.125 \\
\hline & 6.63 & 3.53 & 7.86 & 4.63 & Groups & 3.000 & 0.097 \\
\hline & & & & & $\mathrm{T} \times \mathrm{G}$ & 0.288 & 0.567 \\
\hline \multirow{3}{*}{$\begin{array}{l}30 \text { s chair stand } \\
\text { (time) }\end{array}$} & 16.56 & $25.33^{\# \# \#}$ & 14.17 & 25.83 \#\#\# & Time & 107.785 & 0.001 \\
\hline & 2.75 & 5.86 & 1.53 & 4.57 & Groups & 1171.705 & 0.001 \\
\hline & & & & & $\mathrm{T} \times \mathrm{G}$ & 2.152 & 0.154 \\
\hline \multirow{3}{*}{$\begin{array}{c}\text { Arm curl (Right, } \\
\text { time) }\end{array}$} & 25.38 & 31.00 \#\# & $22.33 *$ & 29.50 \#\# & Time & 36.774 & 0.001 \\
\hline & 3.72 & 4.50 & 3.85 & 2.61 & Groups & 3.653 & 0.067 \\
\hline & & & & & $\mathrm{T} \times \mathrm{G}$ & 1.166 & 0.290 \\
\hline \multirow{3}{*}{$\begin{array}{l}8 \text { foot up-and-go } \\
\text { (sec) }\end{array}$} & 14.67 & 14.90 & 15.83 & $15.98^{* *}$ & Time & 0.190 & 0.666 \\
\hline & 4.32 & 1.79 & 1.82 & 1.91 & Groups & 3.675 & 0.065 \\
\hline & & & & & $\mathrm{T} \times \mathrm{G}$ & 0.008 & 0.929 \\
\hline \multirow{3}{*}{$\begin{array}{c}\text { PEI (Harvard step } \\
\text { test) }\end{array}$} & 99.09 & 114.57 & 94.24 & $103.76^{\#}$ & Time & 3.813 & 0.065 \\
\hline & 15.13 & 14.15 & 7.09 & 8.75 & Groups & 10.090 & 0.005 \\
\hline & & & & & $\mathrm{T} \times \mathrm{G}$ & 0.130 & 0.722 \\
\hline
\end{tabular}

Values are mean and standard deviation; NBP: normal blood pressure; HNBP: high-normal blood pressure; PEI: physical efficiency index; T: time; G: groups; ${ }^{*} p<0.05,{ }^{* *} p<0.01$ vs. NBP group: Mann-Whitney test between groups; \# $p<0.05, \# \# p<0.01$, \#\#\# $p<0.001$ vs. pre: Wilcoxon test between time.

\subsection{Pro-Inflammatory and Anti-Inflammatory Markers}

Analysis of pro-inflammatory markers revealed significantly greater decreases in the TNF- $\alpha$, IL-6, and SAA levels in the HNBP compare with the NBP group $(p<0.05)$ after the 6 -month exercise program in Table 4. A particularly significant $(p<0.01)$ post-intervention decrease in SAA was observed in the HNBP. In contrast, the NBP did not show any positive effects of exercise. Analysis of anti-inflammation markers revealed a significant increase in the HSP70 level $(p<0.001)$ in the HNBP after the 6-month exercise program. In the NBP group as well, significant increases were observed in ApoA1 $(p<0.05)$, SOD2 $(p<0.01)$, and HSP70 $(p<0.05)$. 
Table 4. Change of HDL function, antioxidant, cell repair and proinflammation markers after exercise.

\begin{tabular}{|c|c|c|c|c|c|c|c|}
\hline \multirow{2}{*}{ Variable } & \multicolumn{2}{|c|}{$\operatorname{NBP}(n=18)$} & \multicolumn{2}{|c|}{ HNBP $(n=12)$} & \multirow{2}{*}{ Source } & \multirow{2}{*}{ F-Value } & \multirow{2}{*}{$p$-Value } \\
\hline & Pre & Post & Pre & Post & & & \\
\hline \multicolumn{8}{|c|}{ HDL function markers } \\
\hline \multirow{3}{*}{$\mathrm{SAA}(\mathrm{ng} / \mathrm{mL})$} & 17.33 & 17.03 & 17.98 & $14.05 * \# \#$ & Time & 3.909 & 0.058 \\
\hline & 3.26 & 4.20 & 3.18 & 0.69 & Groups & 4.048 & 0.054 \\
\hline & & & & & $\mathrm{T} \times \mathrm{G}$ & 2.872 & 0.101 \\
\hline \multirow{3}{*}{ SAA/HDL } & 0.32 & 0.32 & 0.37 & $0.25^{*}, \# \#$ & Time & 11.459 & 0.002 \\
\hline & 0.05 & 0.08 & 0.09 & 0.04 & Groups & 0.205 & 0.654 \\
\hline & & & & & $\mathrm{T} \times \mathrm{G}$ & 9.881 & 0.004 \\
\hline \multirow{3}{*}{ APOA1 (ng/mL) } & 2182.20 & $3841.46^{\#}$ & 2311.20 & 2769.78 & Time & 0.116 & 0.739 \\
\hline & 1818.67 & 1971.41 & 1450.49 & 1297.58 & Groups & 0.141 & 0.713 \\
\hline & & & & & $\mathrm{T} \times \mathrm{G}$ & 6.376 & 0.024 \\
\hline \multirow{3}{*}{ APOA1/HDL-C } & 27.33 & 51.67 & $84.24^{* *}$ & $55.19^{\#}$ & Time & 0.023 & 0.881 \\
\hline & 32.85 & 39.70 & 32.88 & 62.86 & Groups & 6.845 & 0.014 \\
\hline & & & & & $\mathrm{T} \times \mathrm{G}$ & 2.921 & 0.098 \\
\hline \multicolumn{8}{|c|}{ Antioxidant and cell repair markers } \\
\hline \multirow{3}{*}{ SOD2 (pg/mL) } & $50,126.30$ & $56,463.16^{\# \#}$ & $51,464.40$ & $49,984.00$ & Time & 2.863 & 0.102 \\
\hline & $13,904.92$ & $13,360.68$ & $12,462.32$ & $10,517.19$ & Groups & 0.317 & 0.578 \\
\hline & & & & & $\mathrm{T} \times \mathrm{G}$ & 7.418 & 0.011 \\
\hline \multirow{3}{*}{ HSP70 (ng/mL) } & 0.59 & $0.79 \#$ & 0.49 & $0.73^{\# \# \#}$ & Time & 12.721 & 0.001 \\
\hline & 0.25 & 0.47 & 0.09 & 0.08 & Groups & 0.707 & 0.408 \\
\hline & & & & & $\mathrm{T} \times \mathrm{G}$ & 0.129 & 0.722 \\
\hline \multicolumn{8}{|c|}{ Pro-inflammation markers } \\
\hline \multirow{3}{*}{ TNF- $\alpha(\mathrm{pg} / \mathrm{mL})$} & 9.59 & 8.71 & 8.19 & $7.71 *$ & Time & 2.334 & 0.138 \\
\hline & 2.75 & 0.96 & 1.65 & 1.13 & Groups & 5.370 & 0.028 \\
\hline & & & & & $\mathrm{T} \times \mathrm{G}$ & 0.204 & 0.655 \\
\hline \multirow{3}{*}{$\mathrm{CRP}(\mathrm{mg} / \mathrm{dL})$} & 0.630 & 0.820 & 0.537 & 0.652 & Time & 1.754 & 0.196 \\
\hline & 0.511 & 0.667 & 0.281 & 0.596 & Groups & 0.593 & 0.448 \\
\hline & & & & & $\mathrm{T} \times \mathrm{G}$ & 0.106 & 0.748 \\
\hline \multirow{3}{*}{ IL-6 (pg/mL) } & 14.68 & 11.39 & 9.85 & $9.54 *$ & Time & 2.427 & 0.130 \\
\hline & 10.51 & 2.88 & 0.85 & 1.04 & Groups & 2.994 & 0.095 \\
\hline & & & & & $\mathrm{T} \times \mathrm{G}$ & 1.659 & 0.208 \\
\hline \multicolumn{8}{|c|}{ Anti-inflammation markers } \\
\hline \multirow{3}{*}{ IL-15 (pg/mL) } & 22.39 & 17.59 & 20.93 & 17.34 & Time & 4.110 & 0.052 \\
\hline & 11.31 & 8.75 & 10.09 & 6.82 & Groups & 0.087 & 0.770 \\
\hline & & & & & $\mathrm{T} \times \mathrm{G}$ & 0.086 & 0.772 \\
\hline \multirow{3}{*}{ IL-4 (pg/mL) } & 14.41 & 13.88 & 12.83 * & $12.43^{*, \#}$ & Time & 1.535 & 0.226 \\
\hline & 2.03 & 2.40 & 0.45 & 0.61 & Groups & 7.826 & 0.009 \\
\hline & & & & & $\mathrm{T} \times \mathrm{G}$ & 0.032 & 0.860 \\
\hline
\end{tabular}

Values are mean and standard deviation; NBP: normal blood pressure; HNBP: high-normal blood pressure; T: time; G: groups; SAA: serum amyloid A; APOA-1: apolipoprotein A-1; HDL-C: high density lipoprotein cholesterol; SOD2: superoxide dismutases 2; HSP70: hit shock protein 70; TNF- $\alpha$ : tumor necrosis factor $\alpha$; CRP: C-reactive protein; IL-6: interleukin 6; IL-15: interleukin 15; IL-4: interleukin 4; T: time; G: groups; ${ }^{*} p<0.05,{ }^{* *} p<0.01$ vs. NBP group: Mann-Whitney test between groups; \# $p<0.05$, \#\# $p<0.01$, \#\#\# $p<0.001$, vs. pre: Wilcoxon test between time.

\subsection{Estimation of 10-Year Risk of Coronary Heart Disease}

In both pre- and post-intervention estimations, the HNBP group showed a significantly $(p<0.001)$ higher 10-year risk of coronary heart disease than the NBP group in Table 5. However, the intragroup pre-post comparison revealed a significant decrease $(p<0.05)$ after the exercise program. In cardiovascular age as well, the HNBP group was significantly $(p<0.001)$ higher than the NBP group. 
Table 5. The 10-year cardiovascular disease risk according to blood pressure and lipids.

\begin{tabular}{|c|c|c|c|c|c|c|c|}
\hline \multirow{2}{*}{ Variable } & \multicolumn{2}{|c|}{$\operatorname{NBP}(n=18)$} & \multicolumn{2}{|c|}{ HNBP $(n=12)$} & \multirow{2}{*}{ Source } & \multirow{2}{*}{$F$-Value } & \multirow{2}{*}{$p$-Value } \\
\hline & Pre & Post & Pre & Post & & & \\
\hline \multirow{3}{*}{$\begin{array}{c}\text { FRS Your } \\
\text { Heart-10 Risk (\%) }\end{array}$} & 7.98 & 7.47 & $17.63^{* * *}$ & $16.17^{* * *, \#}$ & Time & 4.361 & 0.046 \\
\hline & 2.82 & 2.29 & 6.39 & 5.40 & Groups & 37.561 & 0.001 \\
\hline & & & & & $\mathrm{T} \times \mathrm{G}$ & 1.018 & 0.322 \\
\hline Your & 65.22 & 63.56 & $82.00^{* * *}$ & $81.67^{* * *}$ & Time & 0.479 & 0.494 \\
\hline \multirow{2}{*}{$\begin{array}{c}\text { Heart/Vascular } \\
\text { Age (yr) }\end{array}$} & 9.60 & 9.05 & 6.12 & 6.89 & Groups & 40.191 & 0.001 \\
\hline & & & & & $\mathrm{T} \times \mathrm{G}$ & 0.213 & 0.648 \\
\hline
\end{tabular}

Values are mean and standard deviation; NBP: normal blood pressure; HNBP: high-normal blood pressure; T: time; G: groups; FRS: Framingham risk score; T: time; G: groups; *** $p<0.001$, vs. NBP group: Mann-Whitney test between groups, $\# p<0.05$, vs. pre: Wilcoxon test between time.

\subsection{Correlations between Blood Pressure and Anti-Inflammation Markers}

Analysis of major factors that showed significant pre-post differences in SBP and DBP identified the anti-inflammatory factors, IL-4 and IL-15, as factors with the highest correlation coefficients in Figure 1. In particular, the changed amount of IL-15 was significantly associated with those of SBP and DBP, yielding correlation coefficients of -0.734 and -0.628 , respectively.

$$
\text { A }
$$

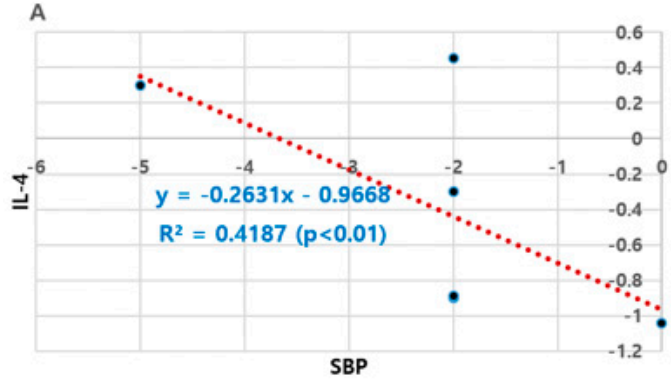

C

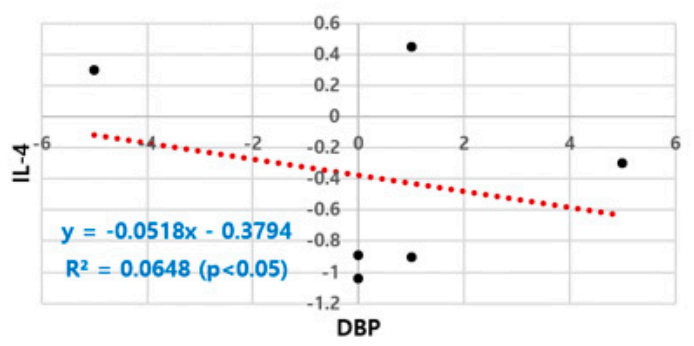

B

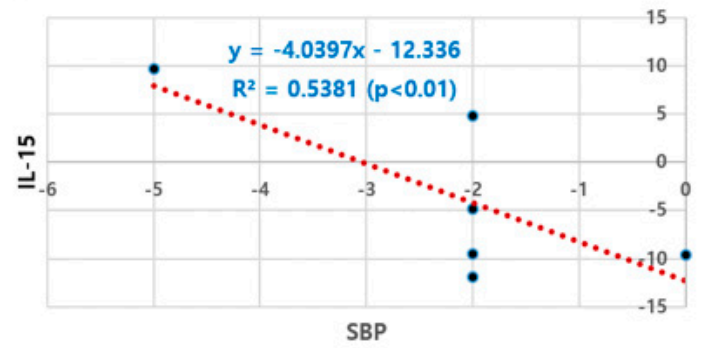

D

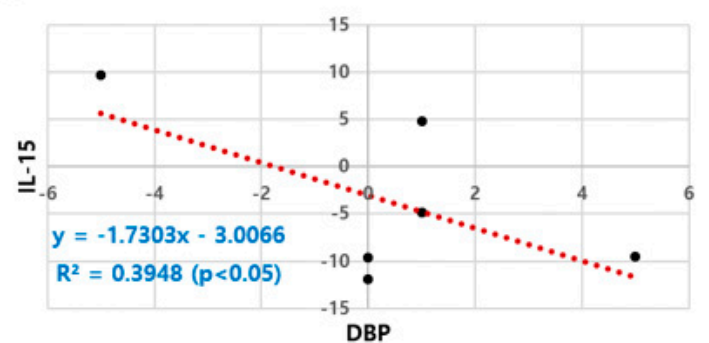

Figure 1. Correlation between blood pressure and anti-inflammation cytokines. (A) SBP vs. IL-4; (B) SBP vs. IL-15; (C) DBP vs. IL-4; (D) DBP vs. IL-15; R2: Pearson's correlation coefficient.

\section{Discussion}

In this study, SBP decreased by $2.1 \mathrm{mmHg}$ in the HNBP group after the 6-month exercise program, and significant improvements were observed across the physical fitness factors after the 6-month intervention program, verifying the positive effects of aerobic exercise programs on reducing blood pressure $[43,44]$. As the most basic step in the factor analysis process related to the post-intervention reduction in post-intervention SBP, which is the typical phenotypic marker or vascular function, changes in the levels of HDL-C and SAA were monitored based on blood lipid variables. Circulating SAA and HDL-C levels are inversely correlated in patients with hypertension and metabolic syndrome, and elevated SAA levels actively inhibit HDL-C's antioxidant activity [45]. A study analyzing the 
association between the CVD mortality rate and SAA level in CVD patients reported that all CVD risk factors were closely associated with elevated SAA levels [46]. In this study, the post-intervention SAA level in the HNBP group was significantly reduced compared with the pre-intervention value. In particular, the HDL-C level also increased significantly after exercise, which allows the assumption that the active aerobic exercise program for the prehypertensive elderly had a positive effect on HDL-C's vaso-protective function. Moreover, in the efficacy analysis process for the prevention and treatment of hypertension and CVD, it was confirmed that SAA plays a more important role, compared with the functional role played by HDL-C, through the changes in the ratio of SAA concentration relative to HDL-C level instead of the absolute levels of HDL-C and SAA. Many studies have advanced the view that exercise improves metabolic and immune functions by improving blood lipids and inflammatory markers. However, the mechanisms mediating the effects of vascular endothelial function and tissue cells are still unclear, and research analyzing the reciprocal effects and close association between the structural change in dysfunctional HDL-C and cardiovascular tissues is still in its infancy. Nevertheless, the positive effect of exercise training will contribute to preventing CVD and metabolic syndrome and reducing the accompanying impairment of physical functions secondary to CVD by reducing the SAA level corresponding to dysfunctional HDL-C, as verified in this study.

The antioxidant function of HDL-C comes into play in close interaction of enzymes, such as Lp-PLA2 (lipoprotein-associated phospholipase A2), PON1 (paraoxonase1), LCAT (lecithin cholesterol-acyltransferase) and GSPx (glutathione selenoperoxidase), and ApoA1 [47-49]. ApoA1 has the strongest antioxidant effect among all Apos in the prevention of LDL oxidation [48], removing oxidized phospholipids from LDL and arterial wall cells [49]. This allows the estimation of CAD according to HDL's pro-inflammatory and anti-inflammatory properties [50], and exercise was expected to reduce the expression of inflammation-related genes by improving modified ApoA1, thus contributing to a chronic inflammatory state transformation CAD reduction [51]. Hypertensive patients have high levels of cellular inflammatory markers as well as cell adhesion molecules [15-17]. However, exercise reduces the levels of circulating IL-6, CRP, and TNF- $\alpha$ [52], and it has also been reported that physical activity in normotensive people is negatively correlated with CRP, fibrinogen, and white blood cell count [53] as well as inflammatory markers including TNF- $\alpha$ and IL-6. In this study, the HNBP group showed a significant decrease in the post-intervention levels of TNF- $\alpha$, Il-6, and SAA, but these inflammatory markers (CRP, TNF- $\alpha$, Il-6, and SAA) showed no significant change in the NBP group, with only the level of ApoA1 significantly increased. It can be said that these differences between groups are difficult to accept as clear results. Therefore, it is thought that continuous research is required to further verification this part. From the finding that exercise training has a direct effect on vascular function and structure in a study analyzing the association between exercise and CVD risk factors [54] and that changes in the traditional cardiovascular risk factors are independent of exercise-induced adaptation with regard to arterial function and health [31], it could be inferred that there is no clear evidence of the correlation between the expression of inflammatory markers and the metabolic function in the course of analyzing the mechanisms of exercise-induced treatment of hypertension and CVD-related risk factors caused by exercise.

Exercise-induced high serum HSP70 level protects the production of atherosclerosis [55], and long-term exercise adaptation maintains a high level of HSP70 protein expression in aorta and myocardium as well as skeletal muscle, leading to higher resistance to myocardial cell stress [56]. According to a study of antioxidant effects of exercise in elderly men (mean age: $62 ; n=18$ ), a 3-month swimming and running exercise program resulted in an increase in plasma SOD2 level [57], and a regular aerobic exercise group showed higher SOD2 level than the sedentary control group [58]. Moreover, HSP70 protein increased in leukocytes in male marathon runners after a half marathon [59], 120-min of rapid cycling in a 22-year-old man led to increase in plasma HSP72 level [60] and increase in serum HSP72 level after a 60-min treadmill exercise [61]. Aerobic and resistance exercise training in the elderly lowers the levels of inflammatory markers such as TNF- $\alpha$, IL-6, and CRP [62-65] and increases myokine such as Il-15, thus playing an anti-inflammatory role [66]. In the current study, 
SOD2 increased significantly after exercise only in the NBP group, but HSP70 increased significantly in both groups, which verified that an exercise program for elderly women can have an antioxidant effect. However, although exercise had the effect of triggering the activity of HSP70 and SOD2 protein in this study, it could not demonstrate the direct effect on cell damage including apoptosis. Therefore, to verify more clearly the effect of preventing and treating hypertension, further research is necessary to analyze the effects of exercise programs reflecting age-dependent appropriate exercise intensity and duration in terms of apoptosis-related factors and cell recovery mechanisms. Furthermore, in view of the lack of change in SOD2 concentration in the HNBP group after exercise, a study will have to analyze the effect of detailed exercise programs considering the participants' general characteristics.

TNF- $\alpha$, a typical inflammatory cytokine, was found to be lower in physically active people than in sedentary people, from which it can be inferred that exercise is associated with the control of inflammatory cytokines, and aerobic and muscle strengthening activities were found to decrease the TNF- $\alpha$ level in older adults [62]. However, a high-intensity aerobic exercise and moderate-intensity muscle strength training intervention in patients with acute heart failure and CAD had no effect on the plasma concentration of TNF- $\alpha$ [67]. Likewise, a study with older adults [68] reported that an aerobic and resistance exercise program had no effect on the TNF- $\alpha$ and IL-6 levels. Taking these results together, there is no clear evidence that inflammatory cytokines vary depending on exercise type, intensity, and duration.

In the current study, the 10-year CVD risk and cardiovascular age were estimated to be significantly higher $(p<0.001)$ in the HNBP group compared with the NBP group, but significantly lower $(p<0.05)$ relative to the baseline value. This leads to the assumption that high blood pressure is closely associated with the prevalence of CVD and hypertension is a risk factor for increasing cardiovascular age, demonstrating that exercise can reduce the risk of CVD prevalence even in hypertensive people. The Framingham Risk Score (FRS) is the sum of the scores calculated from demographic and health-related variables such as gender, age, LDL cholesterol or total cholesterol, HDL-C, SBP, DBP, diabetes, and smoking status as described in the Framingham heart study. It is most widely known as an assessment tool that can predict CVD risk accurately and efficiently by complexly evaluating multiple factors [69]. Although several studies have verified the validity of the FRS [70], its over- or underestimating tendency for specific diseases is still controversial [71]. Moreover, only a limited number of studies has investigated the pre-post differences in the FRS and effects of exercise training treatment. It has also been reported that exercise activity decreases SBP and DBP and improves blood lipid variables [72], and clear improvements in blood pressure and blood lipid variables act as important factors for reducing the FRS [73]. However, as shown in the results of the current study, the exercise program had an effect of improving FRS, but only SBP was significantly reduced among the related detailed factors, which highlights the necessity for continuous study to investigate the overall effects of exercise programs.

In the study of exercise treatment in the elderly, one of the main reasons for the differences in the results regarding the changes in physical fitness, metabolic changes, and inflammatory and anti-inflammatory marker levels is setting the exercise intensity and duration. While most studies are conducted with moderate intensity exercise, no changes in metabolites and inflammatory markers are observed in some studies. According to research results, intense exercise reduces CVD risk factors [74], with high-intensity interval training (HIIT) proving more effective than moderate-intensity exercise in strengthening cardiovascular functions and physical fitness [75], and high- and moderate-intensity exercise in overweight and obesity groups being associated with improvement in cardiometabolic risk factors such as body fat percentage and maximal oxygen intake, which is a blood lipid variable [76]. This study analyzed major variables that have significant effects on the post-intervention changes in SBP and DBP, which are key phenotypic markers of vascular functions, and identified the anti-inflammatory factors, IL-4 and IL-15, as the variables with the highest correlation coefficients. In particular, the amount of change in IL-15 showed significant correlations with SBP and DBP (correlation coefficients: -0.734 and -0.628 , respectively). This leads to the assumption that a small range of post-intervention reduction in anti-inflammatory markers has a positive effect on blood pressure reduction. However, 
no other variables were found to correlate with changes in IL-4 and IL-15 and pathways to better blood pressure. Therefore, in dealing with prehypertensive patients, in-depth studies need be conducted to support the importance of improving blood pressure by activating anti-inflammatory factors. However, it is considered that this study is limited to the elderly in a limited area and the application of the results is very limited considering the very small sample size, and further studies including more subjects are required.

\section{Conclusions}

As a result of a 6-month moderate-intensity active aerobic exercise program administered to prehypertensive elderly women ( $\geq 65$ years), systolic blood pressure was significantly reduced and improvements in vascular function markers could be verified through the improvement of overall physical fitness, including cardiopulmonary endurance, increase in HDL-C, decrease in serum SAA concentration, and substantial decrease in inflammatory biomarkers. It was also verified that exercise training can greatly contribute to reducing 10-year cardiovascular disease risk and that an increase in anti-inflammatory markers, even a small-range increase, can have a great impact on reducing blood pressure.

Author Contributions: Conceptualization, N.A. and K.K.; methodology, N.A. and K.K.; formal analysis, N.A.; investigation, N.A.; resources, N.A.; data curation, K.K.; writing-original draft preparation, N.A.; writing-review and editing, K.K.; visualization, N.A.; supervision, K.K.; project administration, N.A.; funding acquisition, N.A. All authors have read and agreed to the published version of the manuscript.

Funding: This research was supported by a Bisa Research Grant from Keimyung University in 2019 (grant number 2019-0768).

Conflicts of Interest: The authors declare no conflict of interest.

\section{References}

1. Lim, S.S.; Vos, T.; Flaxman, A.D.; Danaei, G.; Shibuya, K.; Rohani, H.A.; AlMazroa, M.A.; Amann, M.; Anderson, H.R.; Andrews, K.G.; et al. A comparative risk assessment of burden of disease and injury attributable to 67 risk factors and risk factor clusters in 21 regions, 1990-2010: A systematic analysis for the global burden of disease study 2010. Lancet 2012, 380, 2224-2260. [CrossRef]

2. Chobanian, A.V.; Bakris, G.L.; Black, H.R.; Cushman, W.C.; Green, L.A.; Izzo, J.L., Jr.; Jones, D.W.; Materson, B.J.; Oparil, S.; Wright, J.T., Jr.; et al. National high blood pressure education program coordinationg committee. Seventh report of the Joint National Committee on prevention, detection, evaluation, and treatment of high blood pressure. Hypertension 2003, 42, 1206-1252. [CrossRef] [PubMed]

3. Egan, B.M.; Stevens-Fabry, S. Prehypertension-prevalence, health risks, and management strategies. Nat. Rev. Cardiol. 2015, 12, 289-300. [CrossRef] [PubMed]

4. Choi, K.M.; Park, H.S.; Han, J.H.; Lee, J.S.; Lee, J.; Ryu, O.H.; Lee, K.W.; Cho, K.H.; Yoon, D.; Bail, S.H.; et al. Prevalence of prehypertension and hypertension in a Korean population: Korean national health and nutrition survey 2001. J. Hypertens. 2006, 24, 1515-1521. [CrossRef] [PubMed]

5. Ortiz, A.; Covic, A.; Fliser, D.; Fouque, D.; Goldsmith, D.; Kanbay, M.; Mallamaci, F.; Massy, Z.A.; Rossignol, P.; Vanholder, R.; et al. Board of the E-mWGoERAE. Epidemiology, contributors to, and clinical trials of mortality risk in chronic kidney failure. Lancet 2014, 383, 1831-1843. [CrossRef]

6. Speer, T.; Owala, F.O.; Holy, E.W.; Zewinger, S.; Frenzel, F.L.; Stahli, B.E.; Razavi, M.; Triem, S.; Cvija, H.; Rohrer, L.; et al. Carbamylated low-density lipoprotein induces endothelial dysfunction. Eur. Heart. J. 2014, 35, 3021-3032. [CrossRef]

7. Williams, B.; Mancia, G.; Spiering, W.; Rosei, E.A.; Azizi, M.; Burnier, M.; Clement, D.L.; Coca, A.; de Simone, G.; Dominiczak, A.; et al. 2018 ESC/ESH guidelines for the management of arterial hypertension. Eur. Heart J. 2018, 39, 3021-3104. [CrossRef]

8. Mancia, G.; Fagard, R.; Narkiewicz, K.; Redon, J.; Zanchetti, A.; Bohm, M.; Christiaens, T.; Cifkova, R.; de Backer, G.; Dominiczak, A.; et al. 2013 ESH/ESC guidelines for the management of arterial hypertension: The task force for the management of arterial hypertension of the European Society of Hypertension (ESH) and of the European Society of Cardiology (ESC). Eur. Heart J. 2013, 34, 2159-2219. 
9. Riwanto, M.; Landmesser, U. High density lipoproteins and endothelial functions: Mechanistic insights and alterations in cardiovascular disease. J. Lipid Res. 2013, 54, 3227-3243. [CrossRef]

10. Coetzee, G.A.; Strachan, A.F.; van der Westhuyzen, D.R.; Hoppe, H.C.; Jeenah, M.S.; de Beer, F.C. Serum amyloid A-containing human high density lipoprotein 3. Density, size, and apolipoprotein composition. J. Biol. Chem. 1986, 261, 9644-9651.

11. Kopecky, C.; Genser, B.; Drechsler, C.; Krane, V.; Kaltenecker, C.C.; Hengstschläger, M.; März, W.; Wanner, C.; Säemann, M.D.M.; Weichhart, T. Quantification of HDL proteins, cardiac events, and mortality in patients with type 2 diabetes on hemodialysis. Clin. J. Am. Soc. Nephrol. 2015, 10, 224-231. [CrossRef] [PubMed]

12. Keeney, J.T.; Swomley, A.M.; Forster, S.; Harris, J.L.; Sultana, R.; Butterfield, D.A. Apolipoprotein A-I: Insights from redox proteomics for its role in neurodegeneration. Proteom. Clin. Appl. 2013, 7, 109-122. [CrossRef]

13. Yazdani, R.; Marefati, H.; Shahesmaeili, A.; Nakhaei, S.; Bagheri, A.; Dastoorpoor, M. Effect of aerobic exercises on serum levels of apolipoprotein $\mathrm{A} 1$ and apolipoprotein $\mathrm{B}$, and their ratio in patients with chronic obstructive pulmonary disease. Tanaffos 2018, 17, 82-89. [PubMed]

14. Agrawal, A.; Hammond, D.J.; Singh, S.K. Atherosclerosis-related functions of C-reactive protein. Cardiovasc. Hematol. Disord. Drug Targets 2010, 10, 235-240. [CrossRef] [PubMed]

15. DeSouza, C.A.; Dengel, D.R.; Macko, R.F.; Cox, K.; Seals, D.R. Elevated levels of circulation cell adhesion molecule in uncomplicated essential hypertension. Am. J. Hypertens. 1997, 10, 1335-1341. [CrossRef]

16. de Faria, A.P.; Ritter, A.M.; Sabbatini, A.R.; Corrêa, N.B.; Brunelli, V.; Modolo, R.; Moreno, H. Deregulation of soluble adhesion molecules in resistant hypertension and its role in cardiovascular remodeling. Circ. J. 2016, 80, 1196-1201. [CrossRef] [PubMed]

17. Komatsu, S.; Panes, J.; Russell, J.M.; Anderson, D.C.; Muzykantov, V.R.; Miyasaka, M.; Granger, D.N. Effects of chronic arterial hypertension on constitutive and induced intercellular adhesion molecule-1 expression in vivo. Hypertension 1997, 29, 683-689. [CrossRef]

18. Ridker, P.M.; Buring, J.E.; Cook, N.R.; Rifai, N. C-reactive protein, the metabolic syndrome, and risk of incident cardiovascular events: An 8-year follow-up of 14719 initially healthy American women. Circulation 2003, 107, 391-397. [CrossRef]

19. Ross, R. Atherosclerosis-An inflammatory disease. N. Engl. J. Med. 1999, 340, 115-126. [CrossRef]

20. Ridker, P.M.; Hennekens, C.H.; Roitman-Johnson, B.; Buring, J.E.; Grodstein, F. Plasma concentration of soluble intercellular adhesion molecule 1 and risks of future myocardial infarction in apparently healthy men. Lancet 1998, 351, 88-92. [CrossRef]

21. Faselis, C.; Doumas, M.; Kokkinos, J.P.; Panagiotakos, D.; Kheirbek, R.; Sheriff, H.M.; Hare, K.; Papademetriou, V.; Fletcher, R.; Kokkinos, P. Exercise capacity and progression from prehypertension to hypertension. Hypertension 2012, 60, 333-338. [CrossRef] [PubMed]

22. Faselis, C.; Doumas, M.; Pittaras, A.; Narayan, P.; Myers, J.; Tsimploulis, A.; Kokkinos, P. Exercise capacity and all-cause mortality in male veterans with hypertension aged $\geq 70$ years. Hypertension 2014, 64, 30-35. [CrossRef] [PubMed]

23. Kokkinos, P.; Manolis, A.; Pittaras, A.; Doumas, M.; Giannelou, A.; Panagiotakos, D.B.; Faselis, C.; Narayan, P.; Singh, S.; Myers, J. Exercise capacity and mortality in hypertensive men with and without additional risk factors. Hypertension 2009, 53, 494-499. [CrossRef] [PubMed]

24. Pareja-Galeano, H.; Garatachea, N.; Lucia, A. Exercise as a polypill for chronic diseases. Prog. Mol. Biol. Transl. Sci. 2015, 135, 497-526.

25. Huang, G.; Shi, X.; Gibson, C.A.; Huang, S.C.; Coudret, N.A.; Ehlman, M.C. Controlled aerobic exercise training reduces resting blood pressure in sedentary older adults. Blood Press. 2013, 22, 386-394. [CrossRef]

26. Beck, D.T.; Martin, J.S.; Casey, D.P.; Braith, R.W. Exercise training reduces peripheral arterial stiffness and myocardial oxygen demand in young prehypertensive subjects. Am. J. Hypertens. 2013, 26, 1093-1102. [CrossRef]

27. Barlow, C.E.; LaMonte, M.J.; Fitzgerald, S.J.; Kampert, J.B.; Perrin, J.L.; Blair, S.N. Cardiorespiratory fitness is an independent predictor of hypertension incidence among initially normotensive healthy women. Am. J. Epidemiol. 2006, 163, 142-150. [CrossRef]

28. Cornelissen, V.A.; Smart, N.A. Exercise training for blood pressure: A systematic review and meta-analysis. J. Am. Heart Assoc. 2013, 2, e004473. [CrossRef] 
29. Jung, M.H.; Ihm, S.H.; Lee, D.H.; Chung, W.B.; Jung, H.O.; Youn, H.J. Prehypertension is associated with early complications of atherosclerosis but not with exercise capacity. Int. J. Cardiol. 2017, 227, 387-392. [CrossRef]

30. Müller, J.; Meyer, J.; Elmenhorst, J.; Oberhoffer, R. Body weight and not exercise capacity determines central systolic blood pressure, a surrogate for arterial stiffness, in children and adolescents. J. Clin. Hypertens. 2015, 18, 762-765. [CrossRef]

31. Green, D.J.; Eijsvogels, T.; Bouts, Y.M.; Maiorana, A.J.; Naylor, L.H.; Scholten, R.R.; Spaanderman, M.E.A.; Pugh, C.J.A.; Sprung, V.S.; Schreuder, T.; et al. Exercise training and artery function in humans: Nonresponse and its relationship to cardiovascular risk factors. J. Appl. Physiol. 2014, 117, 345-352. [CrossRef] [PubMed]

32. Sponder, M.; Kopecky, C.; Campean, I.A.; Emich, M.; Fritzer-Szekeres, M.; Litschauer, B.; Graf, S.; Säemann, M.D.; Strametz-Juranek, J. Sports and HDL-quality reflected by serum amyloid A and surfactant protein B. Int. J. Med. Sci. 2017, 14, 1040-1048. [CrossRef] [PubMed]

33. Niku, K.J.; Oksala, E.; David, E.; Laaksonen, J.; Savita, L.; Nakao, C.; Hänninen, O.; Sen, C.K.; Atalay, M. Heat shock protein 60 response to exercise in diabetes effects of a-lipoic acid supplementation. J. Diabetes Its Complicat. 2006, 20, 257-261.

34. Schmitt, E.; Parcellier, A.; Gurbuxani, S.; Cande, C.; Hammann, A.; Morales, M.C.; Hunt, C.R.; Dix, D.J.; Kroemer, R.T.; Giodanetto, F.; et al. Chemosensitization by a non-apoptogenic heat shock protein 70-binding apoptosis-inducing factor mutant. Cancer Res. 2003, 63, 8233-8240.

35. Rajdev, S.; Hara, K.; Kokubo, Y.; Mestril, R.; Dillmann, W.; Weinstein, P.R.; Sharp, F.R. Mice overexpressing rat heat shock protein 70 are protected against cerebral infarction. Ann. Neurol. 2000, 47, 782-791. [CrossRef]

36. Moran, M.; Delgado, J.; Gonzalez, B.; Manso, R.; Megias, A. Responses of rat myocardial antioxidant defences and heat shock protein HSP72 induced by 12 and 24-week treadmill training. Acta Physiol. Scand. 2004, 180, 157-166. [CrossRef]

37. Durrant, J.R.; Seals, D.R.; Connell, M.L.; Russell, M.J.; Lawson, B.R.; Folian, B.J.; Donato, A.J.; Lesniewski, L.A. Voluntary wheel running restores endothelial function in conduit arteries of old mice: Direct evidence for reduced oxidative stress, increased superoxide dismutase activity and down-regulation of NADPH oxidase. J. Physiol. 2009, 587, 3271-3285. [CrossRef]

38. Trott, D.W.; Gunduz, F.; Laughlin, M.H.; Woodman, C.R. Exercise training reverses age-related decrements in endothelium-dependent dilation in skeletal muscle feed arteries. J. Appl. Physiol. 2009, 106, 1925-1934. [CrossRef]

39. Borg, G. Borg's Perceived Exertion and Pain Scales; Human Kinetics: Champaign, IL, USA, 1998.

40. Rikli, R.; Jones, C. Senior Fitness Test Manual; Human Kinetics: Champaign, IL, USA, 2013.

41. Mattews, D.R.; Hosker, J.P.; Rudenski, A.S.; Naylor, B.A.; Treacher, D.F.; Turner, R.C. Homeostasis model assessment: Insulin resistance and beta-cell function from fasting plasma glucose and insulin concentration in man. Diabetologia 1985, 28, 412-429. [CrossRef]

42. Wilson, P.W.F.; D' Agostino, R.B.; Levy, D.; Belanger, A.M.; Silbershatz, H.; Kannel, W.B. Prediction of coronary heart diseases using risk factor categories. Circulation 1998, 97, 1837-1847. [CrossRef]

43. Leitzmann, M.F.; Park, Y.; Blair, A.; Ballard-Barbash, R.; Mouw, T.; Hollenbeck, A.R.; Schatzkin, A. Physical activity recommendations and decreased risk of mortality. Arch. Intern. Med. 2007, 167, 2453-2460. [CrossRef] [PubMed]

44. Rossi, A.; Dikareva, A.; Bacon, S.L.; Daskalopoulou, S.S. The impact of physical activity on mortality in patients with high blood pressure: A systematic review. J. Hypertens. 2012, 30, 1277-1288. [CrossRef] [PubMed]

45. Dullaart, R.P.; de Boer, J.F.; Annema, W.; Tietge, U.J. The inverse relation of HDL anti-oxidative functionality with serum amyloid a is lost in metabolic syndrome subjects. Obesity 2013, 21, 361-366. [CrossRef] [PubMed]

46. Zewinger, S.; Drechsler, C.; Kleber, M.E.; Dressel, A.; Riffel, J.; Triem, S.; Lehmann, M.; Kopecky, C.; Säemann, M.D.; Lepper, P.M.; et al. Serum amyloid A: High-density lipoproteins interaction and cardiovascular risk. Eur. Heart J. 2015, 36, 3007-3016. [CrossRef] [PubMed]

47. Florentin, M.; Liberopoulos, E.N.; Wierzbicki, A.S.; Mikhailidis, D.P. Multiple actions of high-density lipoprotein. Curr. Opin. Cardiol. 2008, 23, 370-378. [CrossRef]

48. Podrez, E.A. Anti-oxidant properties of high-density lipoprotein and atherosclerosis. Clin. Exp. Pharm. Physiol. 2010, 37, 719-725. [CrossRef] 
49. Navab, M.; Hama, S.Y.; Anantharamaiah, G.M.; Hassan, K.; Hough, G.P.; Watson, A.D.; Reddy, S.T.; Sevanian, A.; Fonarow, G.C.; Fogelman, A.M. Normal high density lipoprotein inhibits three steps in the formation of mildly oxidized low density lipoprotein: Steps 2 and 3. J. Lipid Res. 2000, 41, 1495-1508.

50. Ansell, B.J.; Navab, M.; Hama, S.N.; Kamranpour, N.; Fonarow, G.; Hough, G.; Rahmani, S.; Mottahedeh, R.; Dave, R.; Reddy, S.T.; et al. Inflammatory/antiinflammatory properties of high-density lipoprotein distinguish patients from control subjects better than high-density lipoprotein cholesterol levels and are favorably affected by simvastatin treatment. Circulation 2003, 108, 2751-2756. [CrossRef]

51. Zheng, L.; Nukuna, B.; Brennan, M.L.; Sun, M.; Goormastic, M.; Settle, M.; Schmitt, D.; Fu, X.; Thoson, L.; Fox, P.L.; et al. Apolipoprotein A-I is a selective target for myeloperoxidase catalyzed oxidation and functional impairment in subjects with cardiovascular disease. J. Clin. Investig. 2004, 114, 529-541. [CrossRef]

52. Shlomai, G.; Grassi, G.; Grossman, E.; Mancia, G. Assessment of target organ damage inthe evaluation and follow-up of hypertensive patients: Where do we stand? J. Clin. Hypertens. 2013, 15, 742-747.

53. Totsikas, C.; Röhm, J.; Kantartzis, K.; Claus, T.; Kilian, R.; Jürgen, M.; Fritz, S.; Jochen, H.; Andreas, N.; Andreas, F; i et al. Cardiorespiratory fitness determines the reduction in blood pressure and insulin resistance during lifestyle intervention. J. Hypertens. 2011, 29, 1220-1227. [CrossRef] [PubMed]

54. Green, D.J.; Hopman, M.T.; Padilla, J.; Laughlin, M.H.; Thijssen, D.H. Vascular adaptation to exercise in humans: Role of hemodynamic stimuli. Physiol. Rev. 2017, 97, 495-528. [CrossRef] [PubMed]

55. Zhu, J.; Quyyumi, A.A.; Wu, H.; Csako, G.; Rott, D.; Zalles-Ganley, A.; Ogunmakinwa, J.; Halcox, J.; Epstein, S.E. Increased serum levels of heat shock protein 70 are associated with low risk of coronary artery disease. Arter. Thromb. Vasc. Biol. 2003, 23, 1055-1059. [CrossRef] [PubMed]

56. Kim, S.H.; Ahn, N.Y.; Hong, C.B.; Kim, K.J. The effect of acute and prolonged endurance swim exercise on antioxidant and mitochondrial enzymes in rat skeletal muscle. Exerc. Sci. 2011, 20, 359-366.

57. Ookawara, T.; Haga, S.; Ha, S.; Oh-ishi, S.; Toshinai, K.; Kizaki, T.; Ji, L.L.; Suzuki, K.; Ohno, H. Effects of endurance training on three superoxide dismutase isoenzymes in human plasma. Free Radic. Res. 2003, 37, 713-719. [CrossRef] [PubMed]

58. Pierce, G.L.; Donato, A.J.; Larocca, T.J.; Eskurza, I.; Silver, A.E.; Seals, D.R. Habitually exercising older men do not demonstrate age-associated vascular endothelial oxidative stress. Aging Cell 2011, 10, 1032-1037. [CrossRef]

59. Fehrenbach, E.; Passek, F.; Niess, A.M.; Pohla, H.; Weistock, C.; Dickhuth, H.H.; Northoff, H. HSP expression in human leukocytes is modulated by endurance exercise. Med. Sci. Sports Exerc. 2000, 32, 592-600. [CrossRef]

60. Febbraio, M.A.; Ott, P.; Nielsen, H.B.; Steensberg, A.; Keller, C.; Peter, K.; Secher, N.H.; Pedersen, B.K. Exercise induces hepatosplanchnic release of heat shock protein 72 in humans. J. Physiol. 2002, 544, 957-962. [CrossRef]

61. Walsh, R.C.; Koukoulas, I.; Garnham, A.; Moseley, P.L.; Hargreaves, M.; Febbraio, M.A. Exercise increases serum Hsp72 in humans. Cell Stress Chaperones 2001, 6, 386-393. [CrossRef]

62. Kohut, M.L.; McCann, D.A.; Russell, D.W.; Konopka, D.N.; Cunnick, J.E.; Franke, W.D.; Castillo, M.C.; Reighard, A.E.; Vanderah, E. Aerobic exercise, but not flexibility/resistance exercise, reduces serum IL-18, CRP, and IL-6 independent of beta-blockers, BMI, and psychosocial factors in older adults. Brain Behav. Immun. 2006, 20, 201-209. [CrossRef]

63. Larsen, A.I.; Aukrust, P.; Aarsland, T.; Dickstein, K. Effect of aerobic exercise training on plasma levels of tumor necrosis factor alpha in patients with heart failure. Am. J. Cardiol. 2001, 88, 805-808. [CrossRef]

64. Nicklas, B.J.; Hsu, F.C.; Brinkley, T.J.; Church, T.; Goodpaster, B.H.; Kritchevsky, S.B.; Pahor, M. Exercise training and plasma C-reactive protein and interleukin-6 in elderly people. J. Am. Geriatr. Soc. 2008, 56, 2045-2052. [CrossRef] [PubMed]

65. Kemmler, W.; von Stengel, S.; Engelke, K.; Kalender, W.A. Exercise decreases the risk of metabolic syndrome in elderly females. Med. Sci. Sports Exerc. 2009, 41, 297-305. [CrossRef] [PubMed]

66. Sallam, N.; Laher, I. Exercise modulates oxidative stress and inflammation in aging and cardiovascular diseases. Oxidative Med. Cell. Longev. 2015, 2016, 1-32. [CrossRef]

67. Conraads, V.M.; Beckers, P.; Bosmans, J.; de Clerck, L.S.; Stevens, W.J.; Vrints, C.J.; Brutsaert, D.L. Combined endurance/resistance training reduces plasma TNF-alpha receptor levels in patients with chronic heart failure and coronary artery disease. Eur. Heart J. 2002, 23, 1854-1860. [CrossRef] 
68. Stewart, L.K.; Flynn, M.G.; Campbell, W.W.; Craig, B.A.; Robinson, J.P.; Timmerman, K.L.; McFarlin, B.K.; Coen, P.M.; Talbert, E. The influence of exercise training on inflammatory cytokines and C-reactive protein. Med. Sci. Sports Exerc. 2007, 39, 1714-1719. [CrossRef]

69. Murray, C.J.; Lauer, J.A.; Hutubessy, R.C.; Niessen, L.; Tomijima, N.; Rodgers, A.; Lawes, C.M.M.; Evans, D.B. Effectiveness and costs of intervention to lower systolic blood pressure and cholesterol: A global and regional analysis on reduction of cardiovascular-disease risk. Lancet 2003, 361, 717-725. [CrossRef]

70. Ford, E.S.; Giles, W.H.; Mokdad, A.H. The distribution of 10-Year risk for coronary heart disease among US adults: Findings from the national health and nutrition examination survey III. J. Am. Coll. Cardiol. 2004, 43, 1791-1796. [CrossRef]

71. Brindle, P.M.; Beswick, A.D.; Fahey, T.; Ebrahim, S.B. The accuracy and impact of risk assessment in the primary prevention of cardiovascular disease: A systematic review. Heart 2006, 92, 1752-1759. [CrossRef]

72. Banitalebi, E.; Ghahfarrokhi, M.M.; Faramarzi, M.; Nasiri, S. The effects of 10-week different exercise interventions on Framingham risk score and metabolic syndrome severity scores in overweight women with type 2 diabetes. J. Shahrekord Univ. Med. Sci. 2019, 20, 1-8. [CrossRef]

73. Tully, M.A.; Cupples, M.E.; Chan, W.S.; McGlade, K.; Young, I.S. Brisk walking, fitness, and cardiovascular risk: A randomized controlled trial in primary care. Prev. Med. 2005, 41, 622-628. [CrossRef] [PubMed]

74. Balducci, S.; Zanuso, S.; Cardelli, P.; Salvi, L.; Bazuro, A.; Pugliese, L.; Maccora, C.; Lacobini, C.; Conti, F.G.; Nicolucci, A.; et al. Effect of high- versus low-intensity supervised aerobic and resistance training on modifiable cardiovascular risk factors in type 2 diabetes; the Italian Diabetes and Exercise Study (IDES). PLoS ONE 2012, 7, e49297. [CrossRef] [PubMed]

75. Weston, K.S.; Wisloff, U.; Coombes, J.S. High-intensity interval training in patients with lifestyle-induced cardiometabolic disease: A systematic review and meta-analysis. Br. J. Sports Med. 2014, 48, 1227-1234. [CrossRef] [PubMed]

76. Fisher, G.; Brown, A.W.; Brown, M.M.B.; Alcorn, A.; Noles, C.; Winwood, L.; Resuehr, H.; George, B.; Jeansonne, M.M.; Allison, D.B. High intensity interval-vs moderate intensity-training for improving cardiometabolic health in overweight or obese males: A randomized controlled trial. PLoS ONE 2015, 10, e0138853. [CrossRef] 